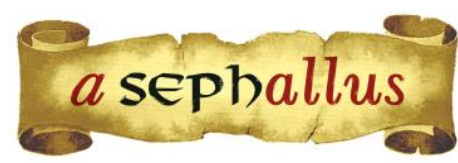

Revista aSEPHallus de Orientação Lacaniana

Núcleo Sephora de Pesquisa sobre o Moderno e o Contemporâneo

ISSN $1809-709 \mathrm{X}$

\title{
A invenção na clínica psicanalítica com crianças em tempos de pandemia
}

\author{
Fernanda Stange Rosi \\ Orcid: 0000-0003-3768-9385 \\ Psicanalista
}

Mestre em Psicologia Institucional pela Universidade Federal do Espírito Santo (Vitória, Espírito Santo, Brasil)

Especialista em Psicologia Hospitalar e da Saúde pelo Instituto Pedagógico de Vitória (Vitória, Espírito Santo,

Brasil)

Graduada em Psicologia pela Universidade Federal do Espírito Santo /UFES (Vitória, Espírito Santo, Brasil)

E-mail: fernanda.stange.rosi@gmail.com

\begin{abstract}
Resumo: Com o advento da pandemia pelo COVID-19, a rapidez com que a decisão de fechar os consultórios precisou ser tomada não permitiu um tempo mínimo de ajuste da clínica aos novos termos. Se inicialmente o atendimento online com crianças pareceu inconcebível, tal cenário exigiu a criação de novas condições de escuta e elaboração, fosse por demanda dos pais, diante de novos sintomas ou do agravamento de quadros de sofrimento já conhecidos, fosse convocado pelas próprias crianças, ligadas ao analista pelo laço transferencial. Assim, coube a cada profissional estabelecer os critérios e condições para o acompanhamento remoto. Quais as especificidades do atendimento infantil que assegurem a ética psicanalítica são possíveis de serem mantidas, mesmo remotamente? O retorno aos fundamentos da clínica permitiu levantar questões sobre a escuta à distância, interrogando não mais se é possível, mas como. É exatamente o que este artigo tenta explorar.
\end{abstract}

Palavras-chave: Psicanálise; Infância; Atendimento online; Transferência; Pandemia.

The invention in the psychoanalytical treatment of children during the pandemic: Along with the spreading of the COVID-19 pandemic and the demand for social distancing that it ensued, psychoanalytic practices had to shut down overnight, not allowing a minimum time period to adjust the clinic to the new terms. If, initially, the online children service seemed inconceivable, such a scenario required the creation of new listening and elaboration conditions, whether at the request of parents, in the face of new symptoms presented or the worsening of the known causes for suffering, or at the request of children themselves, linked to the analyst by the transference bond. Thus, it was up to each professional to establish the criteria and conditions for remote monitoring. What are the specificities of childcare that can be maintained even remotely and that ensure psychoanalytical ethics? The return to the fundamentals of the clinic allowed questions to be raised about listening at a distance, no longer questioning if it is possible, but how to make it possible. This is the topic that this article will to explore.

Keywords: Psychoanalysis; Childhood; Online care; Transference; Pandemic.

L'invention dans la clinique psychanalytique auprès d'enfants en temps de pandémie: Avec l'avènement de la pandémie du COVID-19 et la recommandation qui s'ensuivit de restreindre les déplacements, la décision de fermer les cabinets psychanalytiques a été prise trop vite, sans permettre du temps minimum pour régler la clinique aux nouveaux termes du travail. $\mathrm{Si}$, au début, un soin en ligne avec des enfants semblait inconcevable, le nouveau scénario a exigé la création de nouvelles conditions d'écoute et d'élaboration, soit à la demande des parents, face aux nouveaux symptômes ou l'aggravation des états de souffrance déjà connus, soit convoqués par les enfants mêmes, liées à l'analyste par le lien transférentiel. Donc, c'était à chaque professionnel d'établir des critères et des conditions pour la continuation des travaux à distance. Quelles seront les spécificités du soin des enfants qui peuvent être maintenues même à distance et qui garantissent une éthique psychanalytique? Le retour aux fondements de la clinique a permis de soulever des questions sur l'écoute à distance, en ne demandant plus si c'est possible, mais comment. C'est ce que cet article essaye d'explorer. Mots-clé: Psychanalyse; L'enfance; Soutien en ligne; Transfer; Pandémie. 


\section{A invenção na clínica psicanalítica com crianças em tempos de pandemia}

\section{Fernanda Stange Rosi}

O ano de 2020 entra para a história como um ano de muitas perdas. A velocidade com que vimos disseminado o COVID-19 descortinou não só a pior faceta da disparidade social, ressaltada em um assustador número de mortos, como as consequências diretas de políticas de austeridade em uma grave ameaça à democracia. Aos efeitos da desigualdade e ao desinvestimento contínuo em políticas sociais e de saúde somou-se uma grave crise econômica, deixando todos ainda mais vulneráveis. Se, por um lado, as diferenças se exaltaram, por outro escancarou-se o desamparo, única coisa que verdadeiramente faz de nós irmãos.

Em suas análises acerca do impacto de uma pandemia sobre o mundo, a vida e a sociedade, pensadores de diversos países têm se posicionado, ora com previsões, ora com a impossibilidade delas, o que contribui ainda mais para o sentimento de insegurança. Aos psicanalistas, por sua vez, couberam também as considerações acerca dos efeitos dessa crise sobre o psiquismo e, advertidos de que um analista deve renunciar à sua posição se não puder "alcançar em seu horizonte a subjetividade de sua época" (Lacan, 1998, p. 322), coube também a eles a reinvenção de suas práticas, já que a principal e mais drástica orientação da Organização Mundial de Saúde foi o isolamento social.

Com a pandemia, a rapidez com que a decisão de fechar os consultórios (e não os ouvidos) precisou ser tomada não permitiu um tempo mínimo de ajuste aos novos termos. $O$ isolamento social, indicação unânime dos especialistas para contenção da disseminação do vírus, tornou-se tão imperativo quanto foi imperativo providenciar uma maneira de permitir que os trabalhos de análise continuassem - ou iniciassem, já que uma urgência subjetiva estava também instalada.

Entre muitas dúvidas sobre se uma psicanálise online é possível, o retorno à teoria nos serve como âncora, não nos deixando (tão) à deriva. Um dia, quem sabe, tenhamos "Considerações mais atuais para tempos de guerra, pandemia e morte", atualizando Freud (1915/2010). Por ora, seguimos atentos ao fato de que mesmo em tempos pré-pandêmicos jamais cessamos de nos interrogar sobre quais são as vias possíveis para uma psicanálise. Além disso, quando é que alguma vez pudemos de fato prever os seus efeitos? A pergunta sobre se é psicanálise o que se faz, lá (nos consultórios) ou aqui (do outro lado da linha), não parece exatamente nova. Por fim, tratar-se-ia mesmo de reinventar a clínica? $\mathrm{O}$ que se mantém como fundamento nessa nova modalidade de atendimento ${ }^{1}$ que assegure a direção ética, tão cara à psicanálise?

Nespoli (2020) destaca como "reinventar a clínica" parece ter virado um novo bordão, uma espécie de "Para o alto e avante!", amuleto que, no entanto, não nos garante proteção contra os infortúnios, entre os quais destaca as quedas na transmissão, as falhas de conexão, os delays... Para a psicanalista, são necessárias cautela e reflexão acerca da presença, do ato, do corpo, do olhar, da voz e da transferência: uma profusão de noções e conceitos que precisarão ser perscrutados atentamente ao longo desse novo caminho. Portanto, é fundamental mantermos um certo 
estranhamento com o fato de que o acompanhamento online seja afamado, tão rapidamente e sem interrogações, como um novo nicho de mercado ou estratégia oportuna para tempos de crise. Aos poucos, os atendimentos, mesmo remotos, nos lembram o que realmente se opera nesses encontros: quando a palavra circula, alguma coisa sempre pode advir. Além disso, o inconsciente é insistente em se fazer escutar. O retorno aos fundamentos da clínica psicanalítica permitiu-nos levantar questões sobre a escuta à distância, interrogando não mais se é possível, mas como.

Anteriormente, tínhamos reservas quanto ao atendimento online de adultos. Com a pandemia, oferecemos-Ihes a oportunidade de continuidade da escuta por intermédio das mais variadas tecnologias disponíveis, respeitando não só sua condição psíquica, mas o momento na transferência em que faria diferença abrir mão do objeto olhar, quando as chamadas por vídeo poderiam ser trocadas por chamadas telefônicas. Mas realizar sessões com as crianças através de chamadas de vídeo pareceu, em um primeiro momento, inconcebível. Apesar disso, sabíamos que quanto menor o recurso de linguagem, seja pela idade, seja pela posição subjetiva que ocupa, mais difícil é manejar os limites que o real impõe, o que pode ter efeitos desorganizadores. O contato constante com os pais permitia certo acompanhamento de como cada criança reagia às perdas causadas pela pandemia: a distância da escola, de colegas, professores, familiares, espaços de lazer, até mesmo a perda real de pessoas próximas, mortas pelo vírus, como foi inevitável em alguns casos. A resistência em ofertar a escuta remota também aos pequenos sujeitos precisou ser superada, portanto, quando nos deparamos com novos sintomas ou com o agravamento dos quadros de sofrimentos já em curso. Fosse a pedido dos pais, fosse por meio da demanda das próprias crianças, encorajamo-nos a encarar o desafio. Di Ciaccia (2005) ressalta a importância de que os analistas [no atendimento infantil] se sustentem no Outro desejante, "mesmo que regulado e limitado" (p.46). Para tanto, esse autor destaca como condição a de que cada profissional saiba se portar "em nome próprio, com o próprio estilo, com as próprias capacidades, sabendo pôr em jogo a própria imagem, a própria presença e a própria ausência, os próprios interesses, a própria relação teatral com a vida, com o corpo e com o desejo" (p.47). Pôr-se em jogo, dirá Di Ciaccia, quer dizer assumir, em primeira pessoa, a responsabilidade sobre a invenção na clínica, e acrescentamos que, intermediados pelas telas, talvez ainda mais desejante e ainda mais responsável.

\section{A clínica psicanalítica com crianças}

Toda a construção que permeia o cuidado em saúde mental infantil mostra-se relativamente recente. O período inicial da história da loucura da criança (1800-1875) demarcava apenas o retardo, ou idiotia, como problema mental infantil. Até por volta de 1930, embora contássemos com a publicação dos primeiros tratados de psiquiatria infantil, não parecia possível pensar em um modelo de tratamento para crianças que se diferenciasse dos métodos educativos. Uma verdadeira psicopatologia da infância surge apenas no início do século $X X$, fortemente influenciada pelo avanço das descobertas psicanalíticas (Bercherie, 2001). 
Ao considerar a incidência da linguagem no corpo, tomando-o a partir das marcas da sexualidade, a psicanálise não só se afasta das noções tradicionais de desenvolvimento, mas também introduz elementos importantes a partir de como entende a constituição do sujeito, a transferência e a direção do tratamento. O ensino freudiano, ao propor a incidência da sexualidade infantil e seus efeitos sobre a constituição psíquica, aponta a ressonância da infância sobre a vida adulta, demonstrada vivamente em seus casos clínicos. Estes, por sua vez, deixam claro que a construção teórica em psicanálise é efeito do que a clínica interroga ao analista, como também o atestaram Anna Freud e Melanie Klein, autoras que marcaram pela produção teórica sobre a clínica com crianças. Apesar de não ter se dedicado propriamente a instrumentalizar seus discípulos quanto ao atendimento infantil ${ }^{2}$, Freud (1933/2010) afirma a possibilidade de êxitos radicais e duradouros com a análise de crianças, muito embora a técnica de tratamento precise de algumas modificações. Entre as diferenças consideradas em relação ao adulto tomado em análise, ressalta o fato de que a criança não possui um supereu, bem como não tolera muito os métodos de associação livre. Além disso, dirá que as resistências internas que são combatidas nos adultos estão substituídas, na maioria das vezes, por dificuldades externas. Por fim, aponta particularidades em relação à transferência em decorrência da presença dos pais, sinalizando que "quando os pais se fazem veículos da resistência, frequentemente o objetivo da análise ou ela mesma é ameaçada; por isso é necessário, com frequência, juntar à análise da criança alguma influência analítica sobre os pais" (Freud, 1933/2010, p.309).

Escutar aqueles que se ocupam das funções materna e paterna possibilita ao analista uma primeira leitura das referências em que o sujeito (em formação) se sustenta ou se sustentará, referências que localizam a criança em uma história precedente e facilitam que o seu sintoma seja tomado como uma produção, já que "as manifestações da criança são atos de escrita do texto que cifra a leitura de sua relação com a alteridade" (Vorcaro, 1997, p. 136). Correlato de uma fantasia, representante da verdade do casal parental (Lacan, 1969/1986), o sintoma da criança nos dá sinais sobre como se inscrevem a alienação e a separação, operações constitutivas fundamentais, de acordo com Lacan (1964/2008). Dito de outro modo, pensar na estrutura familiar (social) é pensar nos responsáveis pela transmissão da cultura, pelas identificações, pela inserção na linguagem, pela inscrição da lei.

Em geral, uma criança é encaminhada aos consultórios psicanalíticos sempre que há sinais de sofrimento, de entrave ao desenvolvimento ou à constituição psíquica. A posição psicanalítica a respeito da infância sustenta essa fase da vida como um tempo de não-definição, em que o laço com o Outro é condição para o surgimento do sujeito de desejo, rejeitando, desse modo, considerações diagnósticas fechadas e inflexíveis. Com Vorcaro (2015), reforçamos a compreensão de que haja sempre uma certa implicação do sujeito frente a qualquer fator que porventura venha a afetá-lo (interno, externo, orgânico, social etc.). Um dos maiores feitos da psicanálise, afinal, é mostrar como o sintoma se vincula intimamente com o sujeito, sendo um modo de defesa ou solução de compromisso que ele já encontrou para viver no mundo. 
No que tange ao atendimento de crianças, a atividade lúdica é considerada pela psicanálise como um insistente trabalho de elaboração. O brincar, tomado como equivalente formal da associação livre, permite ao analista que se arrisca à esta clínica um manejo bastante específico da técnica de interpretação. Com efeito, é por meio dos jogos que a criança é capaz de organizar os significantes recebidos do Outro e fazer assentar as marcas da estruturação psíquica. Quando estes marcos, vindos do Outro, entretanto, não se sustentam nem permitem à criança "desdobrar o brincar até as suas últimas consequências" (Coriat, 1997, p. 193), um analista pode integrar algum elemento neste lugar do Outro da criança. A interpretação que a transferência permite, nas psicopatologias infantis, exige, afinal, uma suposição de sujeito, pelo analista, às vezes mesmo antes que haja um. Para que isso seja possível, o desejo do analista se faz suporte dessa aposta imaginária que "estica os signos em que a criança se atrela, até a produção de uma frase, de um dizer" (Vorcaro, 1999, p.99). Para isso, o analista opera um certo empréstimo do seu imaginário para auxiliar na leitura da manifestação da criança:

É com um texto imaginário que o analista veicula o simbólico, desabotoando os signos a que a criança está aderida, para fazer deles significantes. É com esse texto que ele calcula a interpretação, entendida como a extensão metonímica em que o analista implica a criança numa rede discursiva. $O$ analista engaja-se na manifestação da criança, estendendo a produção significante, contando com seu imaginário que: repete, em ato, a manifestação da criança; faz-se de endereço para a ação da criança, tomando-a como um ato subjetivo; reendereça-se à criança; produz uma condição de impossibilidade de reprodução que faz forçagem para que a criança responda de outra maneira (Vorcaro, 1999, p. 99).

Isso não quer dizer, entretanto, ainda de acordo com a mesma autora, que o analista possa embarcar em uma relação de correspondência biunívoca. Segundo Neves \& Vorcaro (2010), ao tratarem do ato analítico com crianças, o fazer do psicanalista está apoiado no funcionamento inconsciente, inserido no campo da palavra e da linguagem e, desde que sob efeito da transferência, possibilita que um corte seja operado:

O psicanalista sustenta uma posição de sujeito suposto saber, no entanto não confunde sua posição com a dos pais. Ainda que em alguns casos seja importante exercer suplência do Outro primário, efetuando um agenciamento da função materna, a sua função não se confunde ou se limita a isto. Como vimos, o sujeito suposto saber é apenas um terceiro no fenômeno da transferência, que ocorre de um outro ao Outro. Portanto, o psicanalista faz uso da transferência e sustenta o lugar de sujeito suposto saber, mas não se encarna como o saber último. A finalidade é a de restabelecer o laço que estava partido no seio familiar e no campo social, e não substituir ou equivaler sua posição com a dos pais nesta dinâmica (Neves \& Vorcaro, 2010, p. 394, itálico nosso). 
Antes que uma criança possa ser surpreendida pelas próprias manifestações, a ponto de perguntar-se sobre elas, parte dos pais a suposição de um saber no analista, abrindo as portas para a formação do laço transferencial de que depende todo o trabalho. Isso faz com que, impreterivelmente, o profissional precise localizar e diferenciar os sujeitos que formulam a demanda nos atendimentos infantis, o que implica a atenção aos discursos prevalentes na cultura e no cotidiano de cada família. Interrogar o sentido dos sintomas levando em conta os discursos e categorias nas quais a criança é encaixada pela medicina, pela escola e por seus cuidadores diretos, não pode, entretanto, impedir de reconhecer seus modos singulares de defesa, de funcionamento e de resposta ao que se passa, tomando-a, afinal, como "um analisante em plenos direitos" (Lefort, 1991, p.11).

A importância de sempre considerar o modo próprio como cada sujeito é afetado e responde ao que ele vive deve ser reforçada neste momento de crise causada pela ocorrência da pandemia pelo COVID-19, por um lado, para que não tornemos problemática a vivência de certas crianças que se mostrem mais ativas em dar contorno às mudanças inevitáveis, patologizando, assim, comportamentos e reações completamente compreensíveis; por outro lado, devemos cuidar para que não tomemos como suposto e previsível o sofrimento manifesto, sem dar a ele a devida atenção, negligenciando uma angústia que a criança ainda não esteja preparada para suportar e, além disso, que essas particularidades, no caso-a-caso, sirvam para avaliar e decidir sobre as condições do trabalho analítico, reconhecendo os limites do tratamento online e assumindo os riscos de contágio pelo vírus quando os riscos subjetivos se mostrarem maiores, ocasião em que o encontro (seguindo todas as orientações das instituições competentes e servindo-se mais uma vez da criatividade, é claro) for indispensável.

\section{A invenção na clínica em tempos de pandemia}

A orientação de isolamento social para controle do contágio pelo Corona vírus, acatada assim que os primeiros números foram contabilizados, interrompeu de forma abrupta os acompanhamentos em consultório. Alguns de longa data, outros ainda no início, todos eles suspensos de maneira problemática pelo simples fato de não ter sido possível uma despedida ou o estabelecimento de alguns combinados, especialmente nos casos de atendimentos infantis, entre analista, a criança e seus pais. Ademais, não sabíamos a duração desse afastamento e ainda tínhamos a esperança de que fosse breve. $O$ passar das semanas e o aumento exponencial do número de infectados e de mortos nos fazia perceber o quanto esse distanciamento se estenderia, mobilizando-nos para alguma retomada. Mas como?

A dificuldade inicial não impediu a transposição dos atendimentos de muitos adultos para o modo online, respeitando o tempo de adequação à mudança, a escolha das melhores vias, os ajustes ao longo das sessões (quanto ao uso de fones, das chamadas de vídeo, a análise sobre se seria possível dispensar o olhar e passar para as chamadas de voz etc.). Respeitou-se, além disso, os 
limites de cada sujeito. Se a psicanálise não é para qualquer um, a psicanálise por telefone, menos ainda, já que se somam outras adversidades inerentes ao novo cotidiano estabelecido.

Quanto ao atendimento infantil, à princípio os telefonemas e trocas de mensagens com os pais, ainda que sabidamente insuficientes, davam notícias sobre como a família e a criança estavam lidando com o novo cenário, de mudanças tão repentinas quanto assustadoras. Na terceira semana de isolamento, Pedro, uma criança que tem nove anos e um diagnóstico de autismo, pede à mãe que telefone para a analista. Desejava falar-Ihe. Faz-se importante saber que ao longo dos dois anos de acompanhamento em consultório, Pedro falou pouquíssimo. Nesta ligação, por vídeo, ele se esforça para dizer que não podia ir ao nosso encontro habitual por causa da pandemia e os dois podem, ao fim da conversa, compensar a despedida que não aconteceu. Foi preciso que Pedro solicitasse mais duas ligações para que essa analista se encorajasse a estabelecer um horário semanal, em retomada às sessões. Pedro escolheu escrever por não se sentir à vontade com o olhar e a voz exigidos pelas chamadas por vídeo. Ceder com a voz e com o olhar era difícil para ele mesmo antes da pandemia, nos atendimentos presenciais, em função de sua condição subjetiva marcada por acentuados traços autísticos: dificuldade de comunicação verbal, a ausência de contato visual, fechamento relacional, linguagem estereotipada ou estereotipias, dentre outros. Por mensagens de texto, Pedro construía uma narrativa sobre a experiência de isolamento, de quebra da sua rotina, tão importante para ele, enumerando todos os lugares que visitaria assim que pudesse sair de casa. Pouco depois, Pedro passou a aceitar retornar às chamadas de vídeo, atendendo a um pedido de sua analista, e tem conseguido responder, em alto e bom som, suas perguntas, estabelecer pequenos jogos, em que desenham juntos (apesar de cada um em sua casa) e mostram os resultados no fim do tempo estipulado. Com mais alguns meses de encontros virtuais, Pedro mostra ainda menos dificuldade em responder à analista, contar pequenos eventos da semana e mesmo relatar alguns sonhos. Recentemente, tem se interessado pela questão das origens da vida e sua maneira de interrogar os mistérios do corpo foi introduzir os sistemas (respiratório, nervoso, digestório e, claro, reprodutivo) e suas minúcias no jogo de forca.

Recolher os efeitos do acompanhamento virtual de Pedro ainda levará um tempo e talvez produza material para outro trabalho. Por enquanto, podemos dizer que se destacam dois aspectos como possíveis facilitadores do trabalho remoto: em primeiro lugar, sem dúvidas, o desejo da analista. Em seguida, que as suas intervenções sejam menos invasivas e direcionadas, haja vista a distância física e o manejo com a posição que a analista ocupa diante da câmera, ao mesmo tempo dentro e fora de enquadre. Além disso, o olhar em uma chamada de vídeo é, obrigatoriamente, não direcionado. Lembrem-se de que para encontrar o rosto do outro lado da tela, o analista precisaria olhar para o ponto de captura da imagem, e não para a imagem projetada, como naturalmente nos é inevitável. Em se tratando de uma criança autista, poderíamos pensar em um pequeno desencontro que age como facilitador do encontro? Respeitar as defesas que ele foi capaz de construir sempre foi uma direção clínica e, mesmo online, leva-se em consideração as dimensões do chamado e do endereçamento característicos da dinâmica invocante, como indicam Catão e Vivès (2011): 
que ele [o analista] se ofereça como um Outro que não seja muito presente, um pouco incompleto, furado, que não demande nada. Ou, então, que demande ao lado, mas que seja secretário das invenções da criança e que as legitime como produção de um sujeito suposto. Escutar a criança autista não somente é possível, mas implica sempre menos do que supomos: um esvaziamento de gozo também por parte do analista (p. 89).

O caso de $\mathrm{Ana}^{3}$, criança com onze anos de idade, foi um pouco diferente. Sua mãe, ao notar uma piora no quadro de angústia, refletida em uma enorme dificuldade em Ana para dormir sozinha medo que já não a acompanhava há uns meses, solicita "como for possível", voltar aos atendimentos da filha. Concordamos que não se tratava de uma urgência e que seria possível ao menos tentar estabelecer o contato remoto. A posição subjetiva da criança, indicativa de um encaminhamento neurótico, faz com que seja mais simples conduzir o novo formato da sessão, também por videochamada. Ana, aliás, apresenta, como muitas outras crianças da sua idade, uma surpreendente destreza com o aparelho celular. É capaz de operar o dispositivo móvel sem o auxílio de sua mãe e parece perfeitamente à vontade com ele - exceto ao acordar, quando Ihe incomoda o embaraço dos cabelos. Ana prefere conversar a jogar. E propôs sessões mais curtas, o que tem sido respeitado. Se para a analista, em certo momento, estava desconfortável a manipulação excessiva do celular pela criança durante a sessão virtual, transformar isso em uma brincadeira em que simulavam uma montanha russa serviu para restabelecer o momento de aterrissar, produzindo um acordo sobre a escansão no movimento.

São duas vinhetas clínicas que mostram particularidades bastante interessantes entre uma criança e outra. Nesses dois casos, em comum vemos uma retomada que não partiu da analista, por pura inaptidão com pandemias e clínica online, muito embora estivesse disponível para isso desde o início do confinamento domiciliar. Que tenha partido dos pais ou, ainda melhor, da própria criança, serve à analista como um aceno do laço transferencial anteriormente estabelecido, fazendo uma aposta nesse lugar (que se ocupa sem ocupar) de suposto saber. Que algo tenha sido endereçado por uma criança autista, a quem o apelo ao Outro se faz tão comprometido, só enseja o desejo da analista e a coragem de enfrentar os percalços tecnológicos deste novo formato de acolhimento. Igualmente, se os pais se esforçam para vencer o receio inicial diante dos perigos cibernéticos para liberar o uso do celular (antes restrito e agora tão necessário), em privacidade (condição acordada com a analista), não pode representar outra coisa que não confiança na direção do tratamento. Disponibilizar um espaço com privacidade ainda não foi possível para Pedro, mas por motivos operacionais: a mãe atua como uma grande auxiliar nas sessões, facilitando a conexão dos aparelhos e a permanência de Pedro diante da tela (enquanto ele concorda em estar, é claro). Também nesse aspecto, vemos avanços. Pedro, vendo a analista usar fones, solicita à mãe os mesmos instrumentos. Com fones, alguma reserva está colocada. 
Se no consultório é a analista quem providencia a estrutura adequada aos atendimentos, com a oferta do material, a organização do setting, reforçando os limites entre a presença dos pais e o espaço sigiloso para o desenrolar das sessões com a criança, agora a mediação dos cuidadores é fundamental, estando esses responsabilizados pelas garantias mínimas. Para que isso seja possível, é preciso, antes, que esteja claro o papel da analista e a importância da privacidade para a criança. Além disso, os pais e a própria criança devem, como sempre, sentir-se acolhidos e à vontade para expor qualquer impasse que atravesse o trabalho remoto. Sem dúvida, essa disponibilidade em recolher os efeitos do atendimento online exige ainda mais da analista, que pode se antecipar em provocar espaços de fala, revisão e novos acordos. Se o aparato tecnológico está garantido pelos pais, assim como o material lúdico possível a cada família, o próprio "encontro" apontará novas maneiras de conexão entre a criança e a analista. Diante da escassez de brinquedos e lápis de cor, por exemplo, a analista resgata as brincadeiras de sua própria infância e as transmite à criança, que talvez não as conhecesse de outra maneira. É assim que os jogos de adedonha ou pedra, papel e tesoura, com alguns ajustes, permitem uma boa diversão, desde que estejamos em alerta quanto às tentativas de Ana de burlar as regras, simulando um pequeno delay para que tenha tempo de escolher o instrumento a ser apresentado pela posição dos dedos, de acordo com sua conveniência e desde que vença a escolha da analista. Ou então, de desligar o som da chamada de vídeo enquanto pede, disfarçadamente, auxílio à irmã para escolher uma fruta que comece com a letra I.

A presença dos pais em sessões com crianças bem pequenas já se fazia importante nos moldes convencionais, não apresentando grandes e novas questões na sua vertente remota. Aliás, tem sido interessante perceber uma disponibilidade ainda maior, em alguns casos, para tornar atraente a brincadeira que precisam sustentar sem o apoio corporal e encorajador da analista. Mas suspeitamos de que possa ser fácil apenas quando esses pais já tenham recursos subjetivos para tanto, bem como já tenham sido fisgados pelo prazer compartilhado com seus bebês. Ou a dificuldade talvez se impusesse.

Ainda orientados pela hipótese de Vorcaro (2015) de que as manifestações da criança são estruturadas como uma linguagem, constituindo o texto que ordena sua realidade psíquica (p. 129), destacamos a importância de acolhermos o discurso parental, tomando-o ali, onde toca os acontecimentos constituintes e os desastres perturbadores ou até paralisantes do processo de subjetivação, sempre contingentes. Neste ponto, defende a autora, devemos considerar que tais ocorrências só adquiram valor na rede de significações tecida a partir da resposta singular do próprio sujeito (Vorcaro, 2015, p.119). É posicionando-nos como permanentemente atentos às singularidades que nos rendemos à condição de completa imprevisibilidade da clínica, seguindo abertos à surpresa, como deve ser.

\section{Uma posição ética}

Inicialmente, fez-se importante frisar nossa intenção de debater a invenção na clínica, e não da clínica. Se o leitor pretendia encontrar neste artigo a exaltação do atendimento infantil online e 
suas possíveis vantagens em relação ao encontro presencial, adiantamos que o resultado só poderia ser frustrante. $O$ retorno aos fundamentos psicanalíticos afirma a importância da presença do analista na sustentação de sua função junto à criança. Isso não quer dizer, entretanto, que, em tempos adversos e por tempo determinado, o exercício transferencial não possa autorizar o trabalho terapêutico remoto, permitindo uma presença (em ausência?) mediada pelos acessórios tecnológicos. Neste caso, algumas indicações precisaram ser levadas em consideração.

Para Vorcaro (2015), a clínica psicanalítica com crianças é uma clínica que permite e exige atos, ou seja, "não se trata de uma observação que neutralizaria o clínico, mas que o responsabiliza pela sua intervenção" (p.126). Afirma, além disso, que explicitar a referência sobre o que é o sujeito é fundamental não só para que o clínico possa se situar em relação ao que concebe, mas para problematizar essa mesma referência "a cada vez que o caso clínico o obriga a interrogá-la" (p.126). A autora nos faz compreender a relação entre a singularidade, a aposta, o ato clínico, os pressupostos teóricos e o próprio lugar do analista em sua liberdade de estilo na condução da clínica, sobretudo em momentos como o atual, em que surgem novos aspectos. Com isso, interrogamos ainda mais fortemente as intervenções, clínicas ou medicamentosas, que ambicionam uma certa conduta adaptada, calando, à força, a angústia produzida pela pandemia e pelas transformações que a acompanham e, assim, incorrendo no risco de vermos suturado o lugar do sujeito e de seu sofrimento.

Perseguir uma maneira de atender crianças à distância, resguardando os critérios éticos que a psicanálise nos impõe, exige uma retomada constante da teoria, sem, entretanto, que nos fechemos para as surpresas inerentes aos encontros. Assim como nas sessões tradicionais, mantemos certa suspensão de nossas expectativas e colocamo-nos disponíveis a ouvir e a jogar o jogo possível para cada criança. Tanto melhor que a própria criança possa propor a atividade, quando caberá a nós o empréstimo de algum recurso para torná-la viável. Por trás das telas, redimensionados os objetos voz e olhar, só podemos esperar efeitos imprevisíveis e sustentar a aposta primordial de que o desejo do analista convoque o sujeito a se manifestar.

A situação atípica imposta pela experiência de atravessar uma pandemia faz com que, além disso, coloquemo-nos disponíveis para escutar os cuidadores em suas angústias, muitas vezes indiscerníveis dos novos sintomas da criança. Independentemente da idade, para cada sujeito tratarse-á de criar a própria ficção acerca do enfrentamento do vírus e das perdas por ele ocasionadas, construindo os contornos que the forem possíveis ao real, sempre impiedoso. A interlocução com os pais os ajudará não só a compreender o processo pelo qual a criança passa e os caminhos que consegue tomar para a elaboração, mas também a pensar em saídas facilitadoras dessa proximidade tão radical provocada pelo confinamento domiciliar, cavando brechas de presenças e ausências - que sabemos constitutivas.

\section{Algumas considerações}


Ainda que pareça que para o psicanalista, por sua função, seja mais suportável manejar com o real, sabemos que nunca é sem efeitos. No que tange às adaptações da clínica motivadas pela pandemia do COVID-19, não é rara aos profissionais a impressão de que navegam no barco de Teseu, demonstrado a sua tentativa de acolher e favorecer o trabalho de elaboração daqueles que escuta, ao mesmo passo em que eles mesmos se esforçam para conter os efeitos desta crise sobre a própria vida, trabalho e desejo. O acompanhamento infantil, comumente já evitado por muitos analistas, encontra novas resistências diante da imposição do atendimento remoto, mesmo entre os mais ousados.

Uma vez aceito o desafio, ao longo desse (novo) processo tem sido importante a interlocução com os pares e a teorização dos impasses clínicos como meio de possibilitar algum avanço, a despeito da situação adversa em que nos encontramos. Foi pensando nisso que, neste artigo, buscamos trazer uma retomada dos principais aspectos relacionados à psicanálise com crianças, desde o lugar do analista, com seu desejo, a participação dos pais e sua influência no trabalho e na transferência, a aposta na subjetividade da criança mesmo quando ainda incipiente e a função do brincar, para, em seguida, sustentar que todos esses fundamentos sejam preservados na modalidade de acompanhamento à distância. $A$ isso nomeamos uma posição ética.

Se trouxemos pequenas vinhetas clínicas para ilustrar a transposição do atendimento presencial para o modo online e o seu andamento, foi apenas para reforçar que, mais uma vez e como sempre, as singularidades precisam ser consideradas desde a decisão de atendê-los remotamente à condução do caso a caso, quando serão considerados o momento estrutural da criança, seu lugar no discurso e o manejo da transferência. Não era nossa intenção trabalhar casos clínicos propriamente ditos, de modo que a escolha das crianças que chamamos de Pedro e Ana se baseou, é claro, em suas diferentes posições subjetivas, para demonstrar possibilidades e o caráter inventivo inerente ao trabalho do psicanalista de crianças. Ainda que de maneira sutil, não deixamos de tocar na resistência que, de acordo com Lacan (1953-43/2009), é sempre do analista - o que também pudemos (confessadamente) constatar, e evocar os pressupostos teóricos e éticos que norteiam esta clínica.

A ideia de que seria necessário inventar a clínica online foi, de saída, abandonada. Em vez disso, demos lugar à invenção na clínica. Afinal, o desejo do analista, responsável por esse manejo criativo, também se alimenta de seus efeitos. Recuperar o prazer na exaustiva nova rotina improvisada nos escritórios, equipada com fones de ouvido, é redobrar a aposta de que a psicanálise, definitivamente, prescinde do setting - como o trabalho em instituições públicas, hospitais e parques ao ar livre já o haviam demonstrado, desde que a flexibilização da técnica analítica se apoie em um rigoroso aporte teórico. Este trabalho, afinal, interroga a respeito do desejo do analista e seu lugar na clínica, um convite a "repensar os móbeis do sujeito-suposto-saber que nesse processo se torna sujeito-suposto-saber-que-há-sujeito e que, supondo isso, chama-o a advir" (Vivès, 2009, p.330), mesmo que, dessa vez, do outro lado da tela. 


\section{Notas}

1. Vale lembrar que o atendimento online já estava regulamentado para os psicólogos desde a Resolução CFP no 11/2012, atualizada pela Resolução CFP no 11/2018, encontrando resistência entre os psicanalistas.

2. Não nos esqueçamos de que com o caso "O pequeno Hans", Freud (1909/2015) inaugura o debate acerca do atendimento infantil na psicanálise, mas que seu interesse maior era confirmar na infância a causa das neuroses e fundamentar sua tese acerca da sexualidade infantil - exposta nos Três ensaios sobre a teoria da sexualidade (Freud, 1905/2016).

3. Assim como Pedro, Ana é um nome fictício.

\section{Referências Bibliográficas}

Bercherie, P. (2001). A clínica psiquiátrica da criança. In O. Cirino (Org.) Psicanálise e psiquiatria com crianças: desenvolvimento ou estrutura. (pp. 129-144). Belo Horizonte, MG: Autêntica.

Catão, I. \& Vivès, J.-M. (2011). Sobre a escolha do sujeito autista: voz e autismo. Estudos de Psicanálise, Belo Horizonte: MG (36), 83-92.

Coriat, E. (1997). A psicanálise na clínica de bebês e crianças pequenas. Porto Alegre, RS: Artes e Ofícios.

Di Ciaccia, A. (2005). A prática entre vários. In M. M. Lima \& S. Altoé (Orgs). Psicanálise, clínica e instituição (pp. 34-54). Rio de Janeiro: Rios Ambiciosos.

Freud, S. (2010). Considerações atuais sobre a guerra e a morte. In Paulo César de Souza (Trad.). Obras Completas (vol. 12, pp. 209-246). SP: Companhia das Letras. (Original publicado em 1915).

Freud, S. (2010). Novas Conferências Introdutórias à Psicanálise. Conferência 34: Esclarecimentos, explicações, orientações. In Paulo César de Souza (Trad.). Obras Completas (vol. 18, pp. 294320). SP: Companhia das Letras. (Original publicado em 1933).

Freud, S. (2015). Análise da fobia de um garoto de cinco anos ("o pequeno Hans"). In Paulo César de Souza (Trad.). Obras Completas (vol. 8, pp. 123-284). SP: Companhia das Letras. (Original publicado em 1909).

Freud, S. (2016). Três ensaios sobre a Teoria da Sexualidade. In Paulo César de Souza (Trad.). Obras Completas (vol. 6, pp. 13-172). SP: Companhia das Letras. (Original publicado em 1905).

Lacan, J. (2008). O Seminário, livro 11: Os quatro conceitos fundamentais da psicanálise. Rio de Janeiro: Jorge Zahar. (Trabalho original publicado em 1964).

Lacan, J. (2009). O seminário, livro 1: os escritos técnicos de Freud. Rio de Janeiro: Jorge Zahar. 1953-1954).

Lacan, J. (1998). Função e campo da palavra e da linguagem. Escritos. Rio de Janeiro: Jorge Zahar, pp. 238-324. (Original publicado em 1953). 
Lacan, J. (1986). Duas notas sobre a criança. Revue du Champ freudien, no 37 (pp.13-14), Traduzido por Durval Checchinato. Recuperada em 15 de junho de 2020, de http://www.acpsicanalise.org.br/docs/duas-notas-sobre-crianca.pdf (Original publicado em 1969). Lefort, R. (1991). Unidade de Psicanálise. In: Miller, Judith (org). A criança no discurso analítico (pp. 11-12). Rio de Janeiro: Jorge Zahar.

Nespoli, N. (2020). Carta aberta publicada em 13 de abril de 2020. Recuperada em 16 de junho de 2020 de https://medium.com/@natlianespoli_27872/vit\%C3\%B3ria-13-de-abril-de-2020438ac837a190

Neves, B. \& Vorcaro, A. (2010). A intervenção do psicanalista na clínica com bebês: Rosine Lefort e o caso Nádia. Estilos da Clínica, 15(2), 380-399. Recuperado em 23 de outubro de 2017, de http://pepsic.bvsalud.org/scielo.php?script=sci_arttext\&pid=S1415-

$71282010000200007 \&$ Ing=pt\&tlng=pt.

Vivès, J.-M. (2009). Para introduzir a questão da pulsão invocante. Rev. Latinoam. Psicopat. Fund., São Paulo, 12(2), pp. 329-341. Recuperado em 26 de Janeiro de 2021, de https://www.scielo.br/pdf/rlpf/v12n2/v12n2a07.pdf

Vorcaro, A. (1997). A criança na clínica psicanalítica. Rio de Janeiro: Companhia de Freud.

Vorcaro, A. (1999). Crianças na psicanálise: clínica, instituição, laço social. Rio de Janeiro: Companhia de Freud.

Vorcaro, A. (2015) Paradoxos de uma psicopatologia psicanalítica de crianças. In M. Kamers, R. Mariotto \& R. Voltolini (Orgs.). Por uma (nova) psicopatologia da infância e adolescência. (pp. 117-148). São Paulo: Escuta.

Citação/Citation: Stange Rosi, F. (nov. 2020 a abr. 2021). A invenção na clínica psicanalítica com crianças em tempo de pandemia. Revista aSEPHallus de Orientação Lacaniana, 16(31), 80-92. Disponível em www.isepol.com/asephallus. Doi: 10.17852/1809-709x.2021v16n31p80-92

Editor do artigo: Tania Coelho dos Santos.

Recebido/Received: 10/03/2020 / 03/10/2020.

Aceito/Accepted: 10/28/2020 / 28/10/2020.

Copyright: (C) 2019 Associação Núcleo Sephora de Pesquisa sobre o moderno e o contemporâneo. Este é um artigo de livre acesso, que permite uso irrestrito, distribuição e reprodução em qualquer meio, desde que 0 autor e a fonte sejam citados/This is an open-access article, which permites unrestricted use, distribution, and reproduction in any medium, provided the author and source are credited. 